Eskişehir Osmangazi Üniversitesi iiBF Dergisi

Nisan 2018, C. 13, S. 1, 129-142

Başvuru : :17.10.2017

Kabul : :23.02.2018

\title{
MIST Borsalarında Rassal Yürüyüş Hipotezi
}

\author{
Eray Gemici ${ }^{1}$ \\ Müslüm Polat ${ }^{2}$
}

MIST Borsalarında Rassal Yürüyüş Hipotezi

Öz

Borsalarda hisse senetlerinin fiyatı arz ve talebe göre belirlenmektedir. Eğer borsada rassal yürüyüş hipotezi geçerli ise geçmiş verilerden hareketle fiyat tahmininde bulunmak mümkün olmamaktadır. Aksi takdirde bu bilgileri kullanan kişiler fiyat tahmininde bulunabilmekte ve normalüstü kazanç elde edebilmektedirler. Bu makalenin amacı MIST ülkelerinde (Meksika, Endonezya, Güney Kore ve Türkiye) Ocak 1998 - Temmuz 2017 döneminde borsa endekslerinin zayıf formda etkin olup olmadığını ortaya koymaktır. Bu amaçla MIST borsalarının rassal yürüyüş süreci 2016 yılında Furuoka tarafından literatüre kazandırılan birim kök testi ile incelenmiştir. Elde edilen bulgular, incelenen piyasaların zayıf formda etkin olmadığına işaret etmektedir.

Anahtar Kelimeler: Etkin Piyasa, Rassal Yürüyüş Hipotezi, Birim Kök Testi

\author{
Random Walk Hypothesis in MIST Stock Markets \\ Abstract
}

Stock prices are determined by supply and demand in stock markets. If the random walk hypothesis is valid in the stock market, it is not possible to estimate the price from the historical data. Otherwise, those who use this information will be able to estimate the price and obtain abnormal earnings. The purpose of this article is to show whether stock market indices are efficient in weak form during the period from January 1998 to July 2017 in the target MIST countries (Mexico, Indonesia, South Korea and Turkey). For this purpose, the random walking process of MIST stock exchanges was examined in 2016 by Unit root test, which was acquired by Furuoka in literature. The findings show that the markets studied are not efficient in weak form.

Keywords: Efficient Market, Random Walk Hypothesis, Unit Root Test

\section{Giriş}

Finans literatüründe uzun yıllar tartışılagelen bir konu olan ancak üzerinde henüz ortak bir fikir birliğinin sağlanamadığı etkin piyasa hipotezi özü itibariyle fiyat değişikliklerinin rassal yürüyüş fikrinden hareket etmektedir. Rassal yürüyüş fikrinin temel mantığı ise, bilgi akışının engellenemez olması ve söz konusu bilginin hisse senetleri fiyatlarına anında yansıması olarak tanımlanabilmektedir. Bu anlamda yarın meydana gelebilecek fiyattaki bir değişim, sadece yarına ilişkin haberlerle ilişkili olacağından bugünkü fiyat değişimleri tamamen bağımsız olmaktadır (Malkiel, 2003: 59). Dolayısıyla hisse senedine ilişkin fiyatlar rassal bir süreci takip ettiğinde, piyasadaki oyuncular getirilere ilişkin tarihsel fiyat değişimlerini tahmin edememekte ve o andaki hisse senedine ilişkin fiyat, gerçek değeri yansıtmaktadır.

Fama, (1965: 56) "Borsa Fiyatlarında Rassal Yürüyüş" isimli makalesinde rassal yürüyüş teorisinin etkin piyasa için iyi bir örnek olduğunu belirtmiş ve etkin piyasayı, tek tek menkul kıymetlerin gelecekteki değerini tahmin etmek üzere kar maksimizasyonu amacıyla çok sayıda rasyonel yatırımcının birbiriyle rekabet halinde olduğu ve güncel önemli bilgilerin tüm katılımcıların eline kolaylıkla geçtiği bir piyasa olarak tanımlamıştır. Ayrıca rassal yürüyüş modeli üzerine

\footnotetext{
${ }^{1}$ Dr. Öğr. Üyesi, Gaziantep Üniversitesi İslahiye IißBF, İşletme Bölümü, gemici@gantep.edur.tr, http://orcid.org/00000001-5449-0568

2 Dr. Öğr. Üyesi, Bingöl Üniversitesi iiBF, İşletme Bölümü, mpolat@bingol.edu.tr, https://orcid.org/0000-0003-11984693
} 
yapılan ampirik araştırmaların ana kaygısının, birbiri ardına gelen fiyat değişikliklerinin birbirinden bağımsız olup olmadı̆̆ının analiz edilmesine yönelik olduğunu ifade etmiştir.

Fama, 1970 yılındaki bir diğer makalesinde 3 tip piyasa etkinliğinden bahsetmiştir. Bunlar (Fama, 1970:383):

1. Menkul kıymetin geçmişine ilişkin tüm bilgilerin fiyata yansımış olduğu zayıf formda piyasa etkinliği,

2. Halka açık tüm bilginin menkul kıymet fiyatlarına yansımış olduğu yarı güçlü formda piyasa etkinliği,

3. Sadece halka açık bilgilerin değil aynı zamanda şirket içi bilgilerin de menkul kıymet fiyatlarına yansımış olduğu güçlü formda piyasa etkinliği.

Hemen belirtmek gerekir ki etkin bir piyasa, mükemmel bir piyasa anlamına da gelmemektedir (Bildik, 2000: 1). Bu noktada etkin piyasa kavramının daha iyi anlaşılması için mükemmel sermaye piyasaları için gerekli özellikleri incelemek gerekmektedir.

Mükemmel sermaye piyasaları için gerekli özellikler şu şekilde sıralanmaktadır (Kıyılar, 1997:9):

- Piyasada yer alan katılımcılar, tüm bilgilere maliyetsiz olarak erişmektedir.

- Katılımcılar rasyoneldir ve seçimlerindeki temel güdü yüksek getiri, düşük risktir.

- Piyasada katılımcılar için herhangi bir işlem maliyeti söz konusu değildir.

- Vergi sistemi piyasa ile ilgili olan herkese tarafsızdır.

- Piyasada yer alan pek çok alıc ve satıcının hiçbirinin piyasayı etkileyebilecek payı yoktur.

- Tüm finansal varlıklar bölünebilir niteliktedir.

Ancak günümüzde bu koşulların sağlanabildiği bir piyasanın varlı̆̆ından bahsetmek oldukça güçtür. Çünkü her yatırımcı, piyasa hakkında tüm bilgilere ulaşamaz ve yatırımcılar yatırım kararı aldıktan sonra farklı oranlarda işlem maliyetine katlanmak durumundadırlar (Karan, 2011:276).

Bu makalenin amacı, MIST ülke borsalarında etkin piyasa hipotezinin geçerliliğini test ederek yatırımcıların bu borsalarda aldıkları yatırım kararlarında hisse senetlerinin gerçek değerine yatırım yapıp yapmadıklarını ortaya koymaktır. Bu bağlamda giriş bölümünü takiben ikinci bölümde etkin piyasa hipotezinin geçerliliğini sınamaya yönelik Türkiye ve diğer ülkelerde yapılan çalışmalar ve bu çalışmalardan elde edilen bulgular özetlenmiştir. Üçüncü bölümde çalışmada kullanılacak veri seti, kullanılan yöntem ve elde edilen bulgular açıklanmış ve çalışma sonuç kısmı olan dördüncü bölüm ile sonlandırılmıştır.

\section{Literatür Tarama}

Literatürde farklı ülkeler için etkin piyasa hipotezinin geçerliliğine yönelik yapılan birçok araştırma mevcuttur. Bu araştırmalarda kullanılan istatistiksel ve ekonometrik testler her ne kadar farklılık gösterse de hemen hemen hepsinde ortak olan nokta bu çalışmanın da konusunu oluşturan finansal serilerin rassal yürüyüş hipotezine uygunluğunu sınamak olmuştur. Tablo 1'de farklı ülkelerde yapılan çalışmalar, çalışmalardan elde edilen bulgular ve çalışmalarda kullanılan istatiksel ve ekonometrik yöntemler özet olarak sunulmuştur. 
Nisan 2018, C. 13, S. 1

Tablo 1: Literatür Taraması

\begin{tabular}{|c|c|c|c|c|}
\hline Yazar/Yıl & Piyasalar & Veri & Yöntem & Bulgular \\
\hline Chan vd. (1997) & $\begin{array}{l}18 \text { uluslararası } \\
\text { piyasa }\end{array}$ & $\begin{array}{l}\text { Ocak 1961- } \\
\text { Aralık } 1992\end{array}$ & $\begin{array}{l}\text { PP Birim Kök ve } \\
\text { Eşbütünleşme }\end{array}$ & Kabul \\
\hline Buguk ve Brorsen (2003) & IMKB & 1992-1999 & $\begin{array}{l}\text { ADF Birim Kök, } \\
\text { GPH Testi, } \\
\text { Variance Ratio } \\
\text { Testi }\end{array}$ & Kabul \\
\hline Narayan ve Smyth (2004) & Güney Kore & $\begin{array}{l}\text { Ocak 1981- } \\
\text { Nisan } 2003\end{array}$ & $\begin{array}{l}\text { ADF Birim Kök, } \\
\text { ZA Birim Kök, } \\
\text { LP Birim Kök }\end{array}$ & Kabul \\
\hline Narayan (2005) & $\begin{array}{l}\text { Avustralya ve } \\
\text { Yeni Zelanda }\end{array}$ & $\begin{array}{l}\text { Avustralya } \\
\text { Ocak } 1960 \\
\text { Nisan } 2003 \\
\text { Yeni Zelanda } \\
\text { Ocak } 1967 \\
\text { Nisan } 2003\end{array}$ & TAR Modeli & Kabul \\
\hline Özdemir (2008) & IMKB & $\begin{array}{l}\text { Ocak 1990- } \\
\text { Haziran } 2005\end{array}$ & $\begin{array}{l}\text { ADF Birim Kök, } \\
\text { LP Birim Kök, } \\
\text { Runs Testi, } \\
\text { Variance Ratio } \\
\text { Testi }\end{array}$ & Kabul \\
\hline Atan vd. (2009) & IMKB & $\begin{array}{l}3 \text { Ocak 2003- } \\
30 \text { Aralık } 2005\end{array}$ & $\begin{array}{l}\text { ADF Birim Kök, } \\
\text { KPSS Birim Kök, } \\
\text { ELW }\end{array}$ & Kabul \\
\hline Ergül (2009) & IMKB & $1988-2007$ & $\begin{array}{l}\text { ADF Birim Kök, } \\
\text { PP Birim Kök, }\end{array}$ & Kabul \\
\hline Borges (2010) & $\begin{array}{l}6 \text { Avrupa Borsası } \\
\text { (Birleşik Krallık, } \\
\text { Fransa, Almanya, } \\
\text { İspanya, Yunanis- } \\
\text { tan ve Portekiz }\end{array}$ & $\begin{array}{l}1 \text { Ocak } 1993 \\
31 \text { Aralık } 2007\end{array}$ & $\begin{array}{l}\text { Runs test, } \\
\text { Variance ratio test }\end{array}$ & $\begin{array}{l}\text { Almanya ve İs- } \\
\text { panya; Kabul }\end{array}$ \\
\hline Munir vd. (2012) & $\begin{array}{l}5 \text { Asya Borsası } \\
\text { (Endonezya, Ma- } \\
\text { lezya, Filipinler, } \\
\text { Singapur ve Tay- } \\
\text { land) }\end{array}$ & $\begin{array}{l}\text { Ocak 1990- } \\
\text { Ocak } 2009\end{array}$ & TAR Modeli & $\begin{array}{l}\text { Malezya ve } \\
\text { Tayland; Kabul } \\
\text { Endonezya, Fi- } \\
\text { lipinler ve } \\
\text { Singapur; Red }\end{array}$ \\
\hline Kapusuzoğlu (2013) & IMKB & $\begin{array}{l}26 \text { Aralık } 1996 \\
30 \text { Kasım } 2012\end{array}$ & $\begin{array}{l}\text { ADF Birim Kök, } \\
\text { PP Birim Kök }\end{array}$ & Red \\
\hline
\end{tabular}


Eskişehir Osmangazi Üniversitesi IïF Dergisi

\begin{tabular}{|c|c|c|c|c|}
\hline Zeren ve Konuk (2013) & $\begin{array}{l}\text { Gelişmekte Olan } \\
\text { Ülke Piyasaları }\end{array}$ & $\begin{array}{l}\text { Arjantin } \\
\text { Brezilya } \\
\text { Çin } \\
\text { Endonezya } \\
\text { Filipinler } \\
\text { Hindistan } \\
\text { Meksika } \\
\text { Malezya } \\
\text { Türkiye } \\
\text { Rusya }\end{array}$ & $\begin{array}{l}\text { ADF Birim Kök } \\
\text { KSS Birim Kök }\end{array}$ & $\begin{array}{l}\text { Hindistan, } \\
\text { Rusya, Arjan- } \\
\text { tin, Endo- } \\
\text { nezya, Mek- } \\
\text { sika ve Tür- } \\
\text { kiye;Kabul } \\
\text { Brezilya, Çin, } \\
\text { Filipinler ve } \\
\text { Malezya; Red }\end{array}$ \\
\hline Gözbaşı vd. (2014) & Borsa İstanbul & $\begin{array}{l}1 \text { Temmuz 2002- } \\
7 \text { Temmuz } 2012\end{array}$ & $\begin{array}{l}\text { Doğrusal Olmayan } \\
\text { Birim Kök Testleri }\end{array}$ & Kabul \\
\hline Mishra vd. (2015) & Hindistan Borsası & $\begin{array}{l}\text { Ocak 1995- } \\
\text { Aralık } 2013\end{array}$ & $\begin{array}{l}\text { LM Birim Kök, Na- } \\
\text { rayan ve Popp Bi- } \\
\text { rim Kök, } \\
\text { Narayan ve Liu } \\
\text { Garch Birim Kök }\end{array}$ & Red \\
\hline Yang vd. (2015) & $\begin{array}{l}\text { MIST Ülkeleri } \\
\text { (Meksika, Endo- } \\
\text { nezya, Güney Kore } \\
\text { ve Türkiye) }\end{array}$ & $\begin{array}{l}\text { Nisan 2004- } \\
\text { Nisan } 2012\end{array}$ & $\begin{array}{l}\text { Ardışık Panel Seçim } \\
\text { Metodu, } \\
\text { Fourier KSS, } \\
\text { Fourier Panel KSS }\end{array}$ & Kabul \\
\hline Tuna ve Öztürk (2016) & Borsa İstanbul & $\begin{array}{l}\text { Ocak 2003- } \\
\text { Eylül } 2015\end{array}$ & $\begin{array}{l}\text { ADF Birim Kök, } \\
\text { LP Birim Kök, Car- } \\
\text { rion-i Silvestre Bi- } \\
\text { rim Kök }\end{array}$ & $\begin{array}{l}\text { ADF ve } 5 \text { yapı- } \\
\text { sal kırılmaya } \\
\text { izin veren Car- } \\
\text { rion-i Silvestre } \\
\text { test sonuçla- } \\
\text { rına göre; Ka- } \\
\text { bul iki yapısal } \\
\text { kırılmalı LP bi- } \\
\text { rim kök testi } \\
\text { sonuçlarına } \\
\text { göre; Red }\end{array}$ \\
\hline Erdem (2016) & $\begin{array}{l}\text { Avrupa ve } \\
\text { Asya-Pasifik } \\
\text { Piyasalar }\end{array}$ & $\begin{array}{l}1 \text { Ocak 2013- } \\
1 \text { Eylül } 2016\end{array}$ & $\begin{array}{l}\text { ADF Birim Kök } \\
\text { PP Birim Kök, KPSS } \\
\text { Birim Kök }\end{array}$ & $\begin{array}{l}\text { Türkiye, Yeni } \\
\text { Zelanda, } \\
\text { Avustralya, } \\
\text { Endonezya ve } \\
\text { Hong Kong; } \\
\text { Red }\end{array}$ \\
\hline
\end{tabular}




\section{Araştırmanın Yöntemi}

\subsection{Prosedür}

Bu çalışmada, Furuoka (2016) tarafından önerilen birim kök testi kullanılmıştır. Bu test özelliği gereği ADF testi (Model A), Fourier ADF (FADF) testi (Model B), ADF-SB testi (Model C) ve FADF-SB testi (Model D) olmak üzere dört farklı ekonometrik yöntemin sınanmasına olanak sağlamaktadır. Dolayısıyla bahsi geçen dört farklı ekonometrik yöntemden hangisinin kullanılmasına karar verilmesi noktasında testlerin birbirlerine karşı da sınanması bu testin üstünlüğüne işaret etmektedir. Testte kullanılan dört modele ilişkin denklem sistemleri aşağıda belirtilmiştir:

$$
y_{t}=\mu+y_{t-1}+\varepsilon_{t}
$$

$y_{t}$ endeks kapanış fiyatlarını temsil etmektedir. $\mu$ deterministik terim $\varepsilon_{t}$ ise hata terimini ifade etmektedir.

Model A: $y_{t}=\mu+\beta_{t}+\varepsilon_{t}$

Model B: $y_{t}=\mu+\beta_{t}+\gamma_{1} \sin \left(\frac{2 \pi k t}{T}\right)+\gamma_{2} \cos \left(\frac{2 \pi k t}{T}\right)+\varepsilon_{t}$

Model C: $y_{t}=\mu+\beta_{t}+\delta D U_{t}+\theta D\left(T_{B}\right)_{t}+\varepsilon_{t}$

Model D: $y_{t}=\mu+\beta_{t}+\gamma_{1} \sin \left(\frac{2 \pi k t}{T}\right)+\gamma_{2} \cos \left(\frac{2 \pi k t}{T}\right)+\delta D U_{t}+\theta D\left(T_{B}\right)_{t}+\varepsilon_{t}$

Modellerde yer alan $\beta$ terimi trend için eğim parametresini, $k$ terimi Fourier yaklaşımı için frekans sıklığını, $\gamma$ terimi trigonometrik terimler için eğim parametresini, $t$ terimi deterministik trendi, $T$ terimi gözlem sayısını, $\pi=3.1416$ ve $\delta$ terimi ise yapısal kırılma kuklaları için eğim parametresini göstermektedir.

$T_{B}$ : Yapısal kırılmanın meydana geldiği kırılma noktasını göstermek üzere, eğer;

$t>T_{B}$ ise $D U_{t}=1$ değilse, $D U_{t}=0$

$\theta$ terimi tek seferlik kırılma kuklası için eğim parametresini göstermek üzere, eğer;

$t=T_{B}$ ise $D\left(T_{B}\right)_{t}=1$ değilse, $D\left(T_{B}\right)_{t}=0$

Birinci model olan ADF testinde (Model $A$ ) yalnızca deterministik terimin ve deterministik trendin eklendiği görülmektedir. İkinci model olan FADF testinde (Model B) deterministik bileşenlere ek olarak, doğrusal olmayan trigonometrik terimler eklenmiştir. Üçüncü model olan ADF-SB testinde (Model C) yapısal kırılmalar için kukla değişkenler ve tek seferlik kırılma için bir kukla değişken eklenmiştir. Son model olan FADF-SB testinde (Model D) ise yukarıda bahsi geçen dört deterministik bileşen eklenmiştir.

Daha sonra aşağıdaki 4 eşitlik tahmin edilmiştir;

Model A: $\Delta y_{t}=\mu+\beta_{t}+\rho y_{t-1}+\sum_{i=1}^{p} c_{i} \Delta y_{t-i}+\varepsilon_{t}$

Model B: $\Delta y_{t}=\mu+\beta_{t}+\gamma_{1} \sin \left(\frac{2 \pi k t}{T}\right)+\gamma_{2} \cos \left(\frac{2 \pi k t}{T}\right)+\rho y_{t-1}+\sum_{i=1}^{p} c_{i} \Delta y_{t-i}+\varepsilon_{t}$ 
Model C: $\Delta y_{t}=\mu+\beta_{t}+\delta D U_{t}+\theta D\left(T_{B}\right)_{t}+\rho y_{t-1}+\sum_{i=1}^{p} c_{i} \Delta y_{t-i}+\varepsilon_{t}$

Model D:

$$
\Delta y_{t}=\mu+\beta_{t}+\gamma_{1} \sin \left(\frac{2 \pi k t}{T}\right)+\gamma_{2} \cos \left(\frac{2 \pi k t}{T}\right)+\delta D U_{t}
$$

$$
+\theta D\left(T_{B}\right)_{t}+\rho y_{t-1}+\sum_{i=1}^{p} c_{i} \Delta y_{t-i}+\varepsilon_{t}
$$

Yukarıda bahsi geçen eşitliklerde yer alan $\rho$ terimi gecikmeli bağımlı değişken için eğim parametresidir, $c$ terimi gecikmeli bağımlı değişkeninin birinci farkının eğim parametresidir, $p$ terimi ise gecikme uzunluğunu göstermektedir.

Dört modelin hepsinde $\rho=0$ için t istatistiği kullanılarak boş hipotez test edilmiştir. Boş hipotez altında $y_{t}$ serisi rassal yürüyüş (random walk) özelliği sergilemektedir. Dolayısıyla $\rho=$ 0 ise seri durağan değildir.

Bu çalışmada Furuoka'yı (2016) takiben, optimal gecikme uzunluğu ( $\tilde{p})$ dört model için 1 (bir) olarak ayarlanmıştır ve maksimum frekans (kmax) Model B ve Model D için 2 (iki) olarak ayarlanmıştır.

FADF test yöntemi (Enders ve Lee 2012) takiben, Model B'deki optimal frekans ( $\tilde{k})$, eşitlik (7)'deki hata kareleri toplamının (SSR) minimize edilmesiyle seçilmiştir.

$$
S S R_{F D F}\left(k^{\prime} \varphi=\inf _{k} S S R_{F D F}(k)\right.
$$

ADF-SB prosedürüne göre (Zivot ve Andrews 1992; Perron vd. 1992), yapısal bir kırılma dışsal olarak değil, içsel olarak belirlenmektedir. Daha spesifik olarak, Model C'deki optimal kırılma konumu $(\tilde{\lambda})$ eşitlik (8)'de ADF-SB istatistiğini ( (DDSS) minimize ederek seçilmektedir.

Kırılma yansıması $(\lambda)$ ise aşağıdaki şekilde hesaplanabilmektedir:

$$
\lambda=\frac{T B}{T}
$$

Optimal kırılma konumu $(\tilde{\lambda})$ içsel olarak aşağıdaki gibi seçilmektedir:

$$
\tau_{D F S}(\tilde{\lambda})=\inf _{k} \tau_{D F S}(\lambda)
$$

FADF-SB prosedüründe, FADF-SB istatistiğinin ( FDDFS) hem kırılma pozisyonuna $(\lambda)$ hem de frekansa $(k)$ hassas olduğunu belirtmek gerekmektedir. Optimal kırılma pozisyonunun yeri ve sıklığı (Furuoka, 2016) tarafından şu şekilde belirlenmiştir:

$$
\tau_{F D F S}(\tilde{\lambda}, \tilde{k})=\inf _{\lambda, k} \tau_{F D F S}(\lambda, k)
$$

(13) numaralı eşitlik, optimal kırılma noktasının yeri ve frekansının FADF-SB istatistiğinin minimum olduğu yerde seçildiği anlamına gelmektedir. Bu çalışmada optimum kırılma pozisyonunun $(\tilde{\lambda})$ ve optimal frekansın $\tilde{k}$ ortak kombinasyonu, (gözlem sayısı 235 ve frekans sayısı 2 için $235 \times 2=470$ olası kombinasyon) arasında bağımlı değişkenin gecikmesi için minimal t-istatistiğini üretecektir. 
Enders ve Lee (2012) tarafından önerilen Fourier fonksiyonu en uygun modeli seçmek için dört alternatif standart $\mathrm{F}$ istatistiği kullanılabilir. Bu durumda, F-istatistikleri şu şekilde verilir:

$$
F=\frac{\left(S S R_{0}-S S R_{1}\right) / q}{S S R_{1} /(T-s)}
$$

Burada $S S R_{1}$ kısıtsız modeldeki kalıntı kareler toplamını (SSR) göstermektedir. $S S R_{0}$ kısıtlı modeldeki kalıntı kareler toplamını göstermektedir. $q$ terimi kısıtların sayısını, $s$ terimi ise kısıtsız modeldeki parametrelerin sayısını temsil etmektedir (Furuoka, 2016).

\subsection{Veri Seti}

Çalışmanın veri setini, MIST ülkelerinin (Meksika, Endonezya, Güney Kore ve Türkiye) Ocak 1998-Temmuz 2017 dönemi borsa endekslerine ait aylık kapanış fiyatlarının logaritması oluşturmaktadır. Veriler www.finance.yahoo.com adresinden elde edilmiştir.

\subsection{Veri Analizi}

Çalışmada her bir seriye ilişkin gözlem sayısı 235 olarak belirlenmiştir. Furuoka (2016) tarafından 10.000 Monte Carlo tekrarlama uygulanarak elde edilen kritik değerler dört test türü (Model A, Model B, Model C ve Model D) için kullanılmıştır. Veriler Gauss 10 programında Fumitaka Furuoka'nın web sitesinden elde edilen kodlar ile analize tabi tutulmuştur.

\subsection{Araştırmanın Bulguları ve Sonuçları}

Çalışmada öncelikle MIST borsa endekslerine ait aylık logaritmik kapanış fiyatlarının zaman yolu grafiği Grafik 1'de verilmiştir. Daha sonra çalışmada ele alınan dört modele ilişkin analizden elde edilen bulgular Tablo 2'de özetlenmiştir.

\section{Grafik 1: Borsa Endekslerinin Logaritmik Kapanış Fiyatları (1998M1-2017M7)}

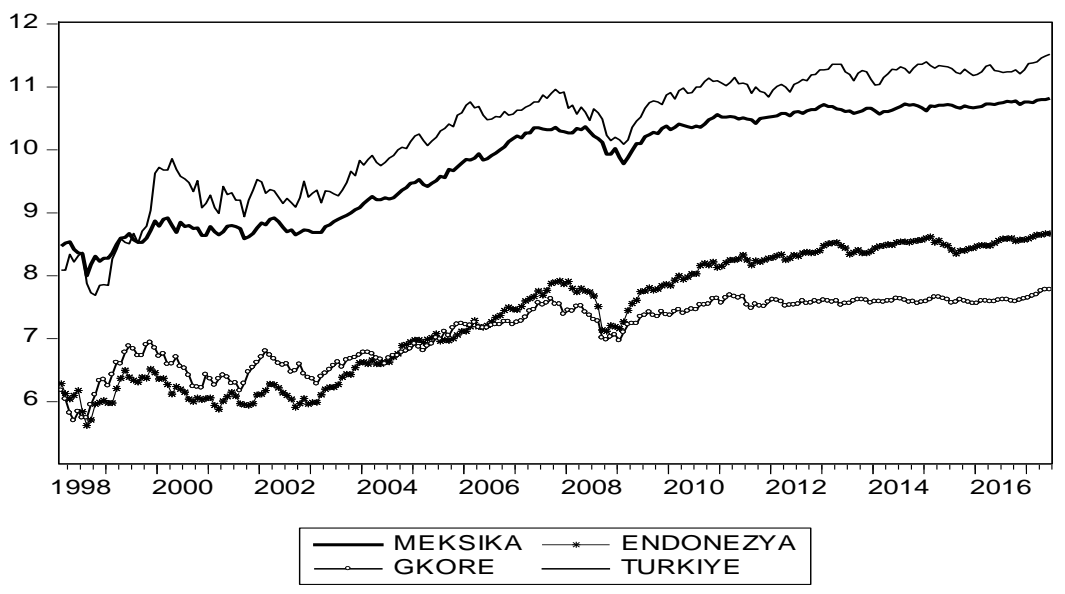


Tablo 2: Analizden Elde Edilen Bulgular

\begin{tabular}{|c|c|c|c|c|}
\hline & Meksika & Endonezya & Güney Kore & Türkiye \\
\hline \multicolumn{5}{|l|}{ ADF test Model A } \\
\hline$\tau_{D F}$ istatistiği & -1.652 & -2.977 & -2.987 & -2.772 \\
\hline \multicolumn{5}{|l|}{ Fourier ADF (FADF) test: Model B } \\
\hline$\tau_{\mathrm{FDF}}$ istatistiği & $-3.102[1]$ & $-3.891[1]$ & $-3.638[1]$ & $-3.355[1]$ \\
\hline $\mathrm{F}_{1}$ istatistiği (Model B vs. Model A) & 4.611 & 4.390 & 2.192 & 1.870 \\
\hline \multicolumn{5}{|c|}{ ADF-yapısal kırılma (ADF-SB) test: Model C } \\
\hline \multirow[t]{2}{*}{$\tau_{F D F}$ istatistiği } & $-3.587^{*}$ & $-4.070 * *$ & $-4.018^{* *}$ & $-4.217^{* * *}$ \\
\hline & $\begin{array}{l}(2004 \mathrm{M} 8 \\
0.34)\end{array}$ & $\begin{array}{l}(2004 \mathrm{M7} \\
0.33)\end{array}$ & $\begin{array}{l}(2005 \mathrm{M} 3 \\
0.37)\end{array}$ & $\begin{array}{l}(1999 \mathrm{M} 1 \\
0.05)\end{array}$ \\
\hline $\mathrm{F}_{2}$ istatistiği (Model C vs. Model A) & $5.504 * *$ & $4.133^{*}$ & $3.9680^{*}$ & $6.196^{* *}$ \\
\hline \multicolumn{5}{|c|}{$\begin{array}{l}\text { Fourier ADF-yapısal kırılma (FADF-SB) test: } \\
\text { Model D }\end{array}$} \\
\hline \multirow[t]{2}{*}{$\tau_{F D F s}$ istatistiği } & $-4.760[1]^{* *}$ & $-5.487[1]^{* * *}$ & $-5.009[1]^{* * *}$ & $-4.612[1]^{* *}$ \\
\hline & $\begin{array}{l}(2008 \mathrm{M} 5 \\
0.53)\end{array}$ & $\begin{array}{l}(2008 \mathrm{M} 4 \\
0.52)\end{array}$ & $\begin{array}{l}(1998 \mathrm{M} 8, \\
0.03)\end{array}$ & $\begin{array}{l}(1999 \mathrm{M} 1 \\
0.05)\end{array}$ \\
\hline $\mathrm{F}_{3}$ istatistiği (Model D vs. Model A) & $5.991^{* *}$ & $6.104^{* *}$ & $6.154^{* *}$ & $4.341^{*}$ \\
\hline $\mathrm{F}_{4}$ istatistiği (Model D vs. Model B) & $7.125^{* *}$ & $7.566^{* *}$ & $9.945^{* * *}$ & $6.718 * * *$ \\
\hline$F_{5}$ istatistiği (Model D vs. Model C) & $11.979 * * *$ & $11.967 * * *$ & $12.105^{* * *}$ & $8.588^{* * *}$ \\
\hline
\end{tabular}

Not: Köşeli parantez içerisindeki sayılar optimal frekans sayısını göstermektedir.

Parantez içerisindeki sayılar kırılma noktasını (TB) ve kırılma pozisyonunu $(\lambda)$ göstermektedir.

*** \%1 düzeyinde anlamlı; ** \%5 düzeyinde anlamlı; * \%10 düzeyinde anlamlı

Tablo 2'de elde edilen bulgular incelendiğinde ADF test (Model A) sonuçlarının dört ülke borsası için rassal yürüyüş hipotezini reddedemediğini göstermektedir. Bir başka ifade ile ADF testinden elde edilen sonuçlar yapısal kırılmalar ve doğrusal dışılık dikkate alınmadan dört ülkenin borsasının durağan olmadığını ve rassal yürüyüş hipotezini desteklediğini göstermektedir. 
Grafik 2: Model A'ya göre Ülkelerin Zaman Yolu Grafiği
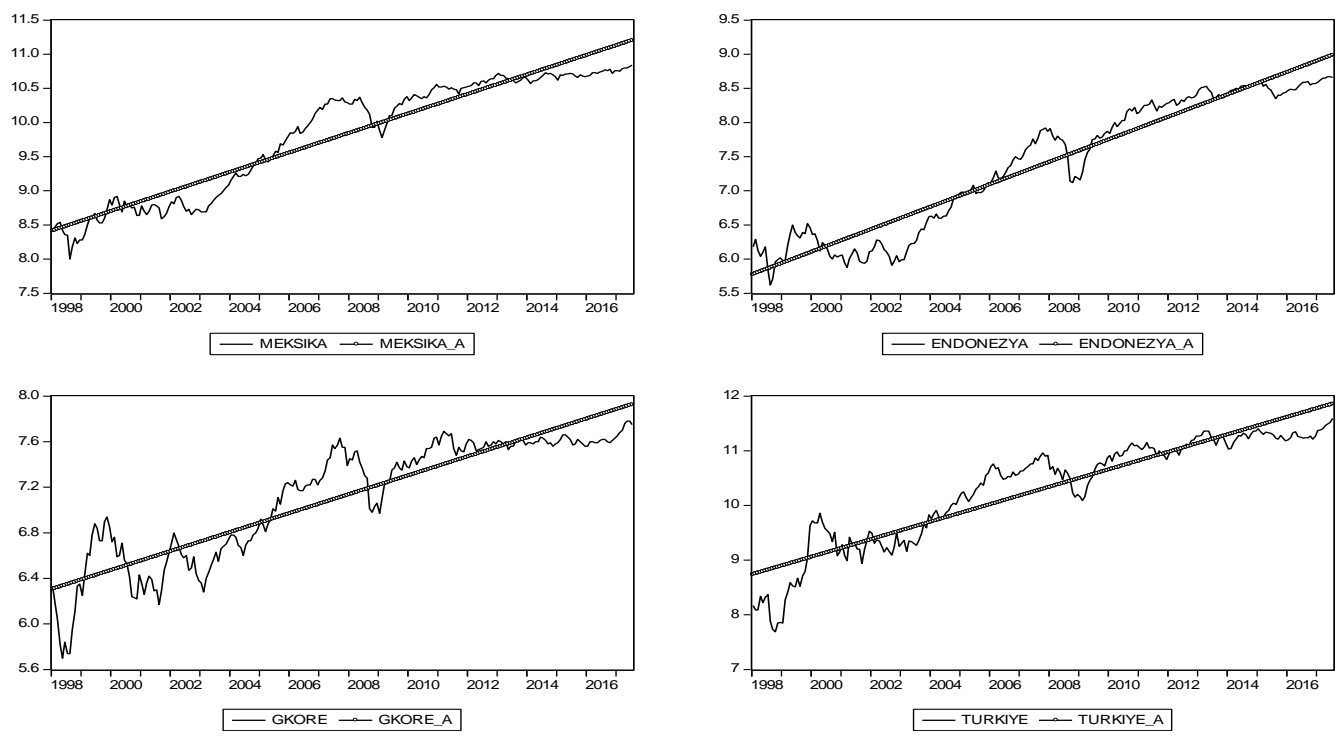

Kaynak: Yazarlar tarafından oluşturulmuştur.

Benzer şekilde FADF testinden (Model B) elde edilen bulgular da dört ülke borsası için rassal yürüyüş hipotezini reddedemediğini göstermektedir. Hangi modelin geçerli olacağına karar verebilmek için Model A'ya karşı Model B'yi sınayan $F_{1}$ istatistik değeri dört ülke borsası için de anlamlı çıkmamıştır. Bu durum dört ülke borsası için de "Doğrusaldır" boş hipotezini reddedemediğini ve rassal yürüyüş hipotezini desteklediğini göstermektedir.

Grafik 3: Model B'ye Göre Ülkelerin Zaman Yolu Grafiği
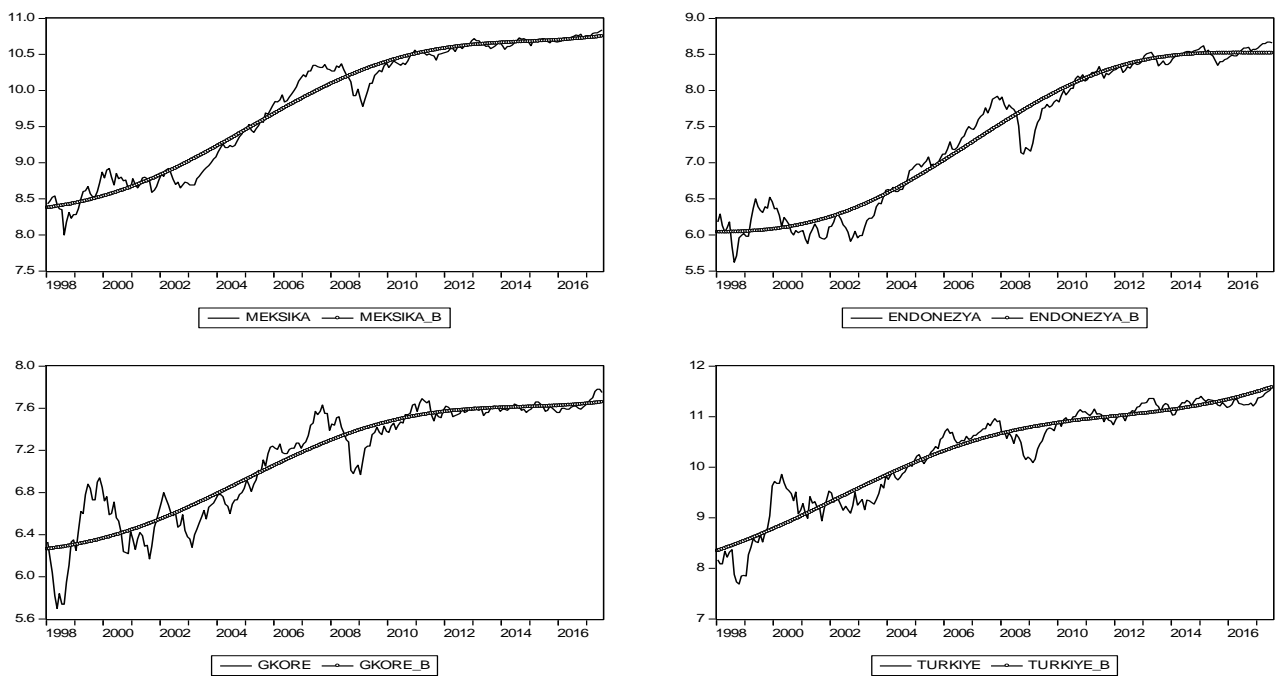

Yapısal kırılmayı da dikkate alan ADF-SB testinden (Model C) elde edilen bulgular dört ülke borsasında yapısal kırılmaların olduğunu göstermektedir. Grafik 4'te görüldüğü üzere Meksika Borsası için ilk kırılma 2004'ün sekizinci ayında gerçekleşmiş ve ardından trend çizgisi yüksel- 
miştir. Endonezya için ilk kırılma 2004'ün yedinci ayında gerçekleşmiş ve devamında trend çizgisi yükselmiştir. Güney Kore için ilk kırılma 1998'in sekizinci ayında gerçekleşmiş ve trend çizgisi yükselmiştir. Son olarak Türkiye için 1999'un birinci ayında gerçekleşmiş ve sonrasında trend çizgisi yükselmiştir.
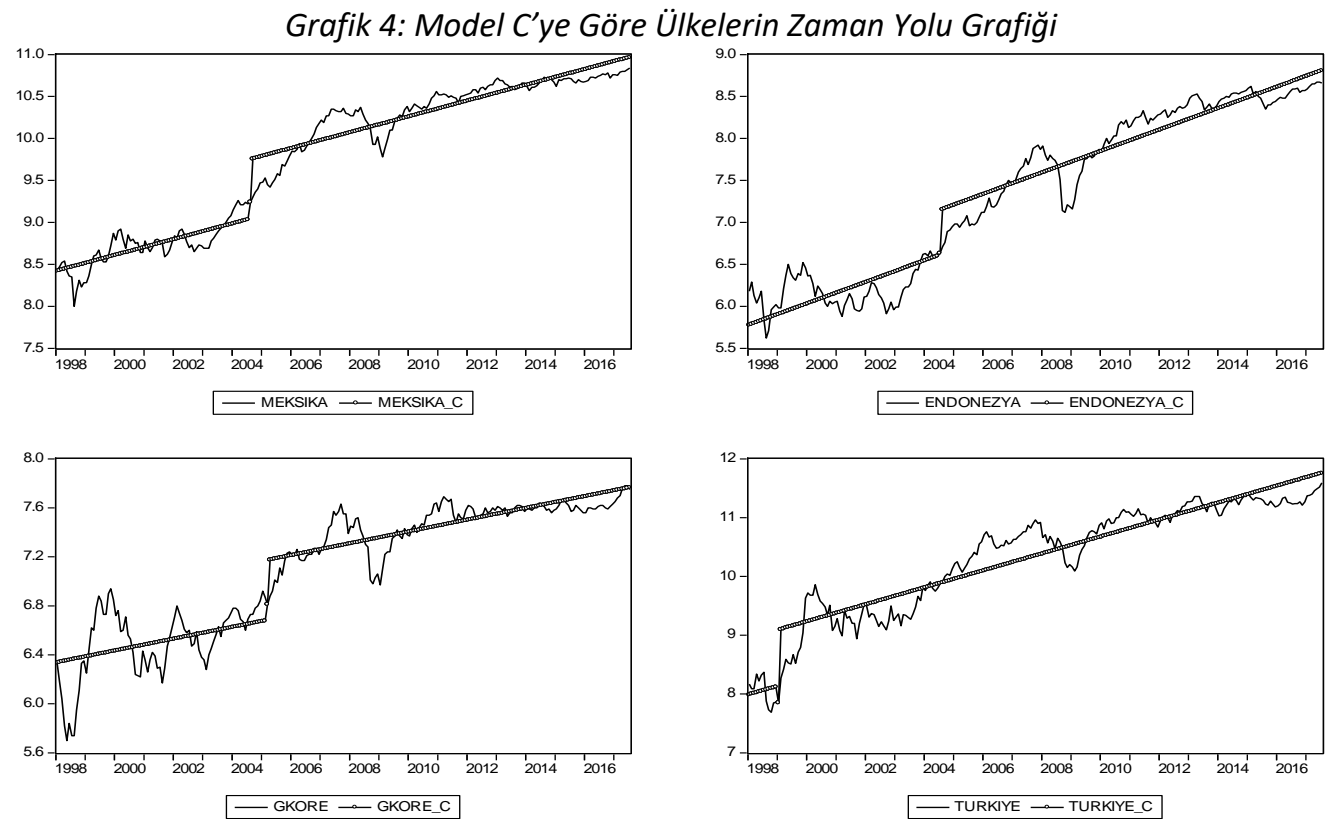

Model C'den elde edilen test istatistikleri dört borsanın tamamı için incelenen serilerin yapısal kırılmalar etrafında durağan olduğunu göstermektedir. Bir başka ifade ile dört ülkenin borsasına ilişkin seriler yapısal kırılmalar etrafında rassal yürüyüş özelliği göstermemektedir. Bu durum yapısal kırılmalar etrafında bu borsaların zayıf formda etkin olmadığını göstermektedir. Diğer taraftan Model A'ya karşı Model $C^{\prime}$ yi sınayan $F_{2}$ istatistiğinin dört ülke için de anlamlı çıkması yapısal kırılmayı dikkate alan ADF-SB (Model C)'nin standart ADF (Model A)'ya göre daha uygun bir model olduğunu göstermektedir.

Son olarak FADF-SB (Model D)'yi; Model A'ya karşı sınayan $F_{3}$ istatistiği, Model B'ye karşı sınayan $F_{4}$ istatistiği ve Model C'ye karşı sınayan $F_{5}$ istatistiği tüm ülkeler için de anlamlı çıkmıştır. Dolasıyla tüm ülke borsaları için optimal modelin Model D olduğu sonucuna ulaşılmıştır. Model D’nin test istatistikleri incelendiğinde ise tüm ülkeler için serilerin rassal yürüyüş özelliği gösterdiğini ileri süren boş hipotez reddedilmiştir. Bu anlamda serilerin durağan olduğunu ve incelenen ülke borsalarının zayıf formda etkin olmadığı sonucuna ulaşılmıştır. 
Grafik 5: Model D’ye Göre Ülkelerin Zaman Yolu Grafiği
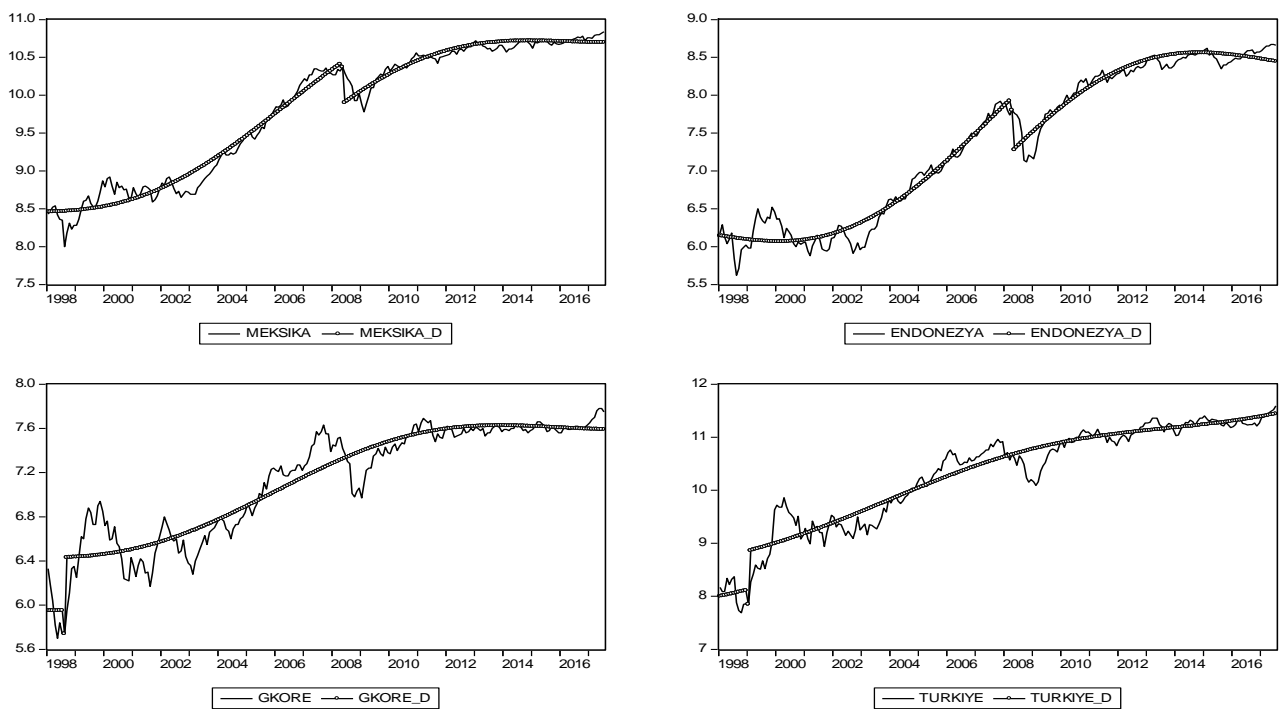

\section{Sonuç}

Günümüzde menkul kıymet borsalarındaki gelişmeler hız kazanarak devam etmektedir. Fon ihtiyacı olan firmalar ihtiyaç duydukları uzun vadeli fonları temin etmek amacıyla menkul kıymet borsalarına yönelirken yatırımcılar da daha fazla kazanç elde etmek için aynı şekilde borsalara yönelmektedirler. Menkul kıymet borsalarında yatırım yapan mevcut yatırımcılar veya yatırım yapmayı düşünen potansiyel yatırımcılar yatırım kararları alırken hisse senedi fiyatının olması gereken değerini hesaplamaktadırlar. Eğer hisse senedi olması gerek tutardan düşük ise alma, yüksek ise satma kararı alırlar. Şayet piyasa etkin bir piyasa ise hisse senedinin fiyatı bütün bilgileri barındırdığı için olması gereken fiyat ile mevcut fiyatı aynı olacaktır. Dolayısıyla böyle bir piyasada normalüstü bir kazanç elde etmek mümkün değildir. Zayıf formda etkin olan bir piyasa ise bütün bilgileri içermese de geçmiş dönemlere ait bilgiyi içermektedir. Dolayısıyla böyle bir piyasada da normalüstü kazanç sağlamak mümkün değildir.

Piyasanın zayıf formda etkin olması bu piyasada fiyatların belirlenmesinde rassal yürüyüş hipotezinin geçerli olduğu anlamına gelmektedir. Rassal yürüyüş, hisse senedinin fiyatında kısa dönemde meydana gelen değişimlerin tesadüfü olduğunu savunur. Dolayısıyla rassal yürüyüş sergileyen bir hisse senedinin fiyatı uzun vadede yukarı ya da aşağı yönlü hareket edebilir. Bu nedenle bir borsada hisse senedi fiyatlarının geçmiş verilerini kullanarak gelecekteki fiyatını tahmin etmenin mümkün olmadığı savunulmaktadır.

Bu çalışmada MIST borsalarında rassal yürüyüş hipotezinin geçerli olup olmadığı araştırılmıştır. Ocak 1998 - Temmuz 2017 dönemine ait aylık verilerin kullanıldığı çalışmada yöntem olarak rassal yürüyüş sürecini; doğrusal, doğrusal olmayan, kırılmalı ve kırılmasız formlarda incelemeye imkan veren Furuoka (2016) birim kök testi kullanılmıştır.

Furuoka (2016) birim kök testinde dört model bulunmaktadır. Bu modellerden birincisi olan Model A, serinin doğrusal olduğu varsaymakta ve kırılmaları dikkate almamaktadır. Çalışmada Model A'dan elde edilen test sonuçlarına göre MIST borsalarının hepsi için rassal yürüyüş hipotezinin geçerli olduğu sonucuna ulaşılmıştır. Ancak gerçek hayatta seriler doğrusaldan ziyade 
doğrusal olmayan biçimdedir. Bunun için ikinci modelde serilerin doğrusal olmadığı varsayımı ile sınama gerçekleştirilmekte ve birinci model ile ikinci modelin hangisinin geçerli olacağına $F_{1}$ istatistiğine bakılarak karar verilmektedir. Çalışmada ikinci modeli (Model B) kullanmanın birinci modele (Model A) göre daha doğru olduğu sonucuna ulaşılmıştır. Bu modele göre de MIST borsalarında rassal yürüyüş hipotezini destekleyen bulgulara ulaşılmıştır. Fakat hem Model $A^{\prime}$ da hem de Model B'de serilerde zaman içinde meydana gelen kırılmalar dikkate alınmamıştır. Serilerin doğrusal ve kırılmalı olduğunu varsayan üçüncü modelde (Model C) incelenen borsalar için rassal yürüyüş hipotezinin geçerli olmadığı belirlenmiştir. Aynı sonuç, serilerin doğrusal olmadığını ve kırılmalar içirdiğini varsayan dördüncü model (Model D) için de tespit edilmiştir. Daha sonra ilk üç model, dördüncü modele karşı sınanmış ve dördüncü modelin geçerli olduğu saptanmıştır. Dolayısıyla MIST borsalarının zaman içindeki değişimlerinin doğrusal olmadığı ve zaman serilerinde kriz ve benzeri sebeplerle kırılmalar olduğu söylenebilir. Bu varsayımlar gerçek duruma oldukça uyumludur. Dolayısıyla bu varsayımlar altında MIST borsalarında rassal yürüyüş hipotezinin geçerli olmadığı söylenebilir. Bu sonuçlar Buguk ve Brorsen (2003), Narayan ve Smyth (2004), Yang vd. (2015), Zengin ve Kurt (2004), Özdemir (2008) ve Atan vd. (2009), gibi çalışmalar ile farklılık gösterdiği görülmektedir. Fakat bu çalışmaların büyük kısmında doğrusal yöntemler kullanıldığı veya kırılmaları dikkate almayan yöntemlerle serilerin test edildiği görülmektedir. Bu çalışmada kırılmalar dikkate alınmadan yapılan ilk iki model (Model A ve Model B) için rassal yürüyüş hipotezi kabul edilirken, bu iki modelin de dördüncü modele karşı geçersiz olduğu belirlenmiştir. Elde edilen bu sonuçlar, Kapusuzoğlu (2013), Mishra vd. (2015) ve Erdem (2016) ile paralellik göstermektedir. 
Nisan 2018, C. 13, S. 1

\section{Kaynaklar}

Atan, Sibel Duman; Özdemir, Zeynel Abidin (2013), “Hisse Senedi Piyasasında Zayıf Formda Etkinlik: IMKB Üzerine Ampirik Bir Çalışma”, Dokuz Eylül Üniversitesi Iktisadi ve Idari Bilimler Fakültesi Dergisi, 24(2).

Bildik, Recep (2000), Hisse Senedi Piyasalarında Dönemsellikler ve iMKB Üzerine Ampirik Bir Çalışma, İstanbul: iMKB Yayınları.

Borges, Maria Rosa (2010), "Efficient market hypothesis in European stock markets", The European Journal of Finance, 16(7), 711-726.

Buguk, Cumhur; Brorsen, B. Wade (2003), "Testing weak-form market efficiency: Evidence from the Istanbul Stock Exchange", International review of financial analysis, 12(5), 579-590.

Chan, Kam C.; Gup, Benton E.; Pan, Ming-Shiun (1997), "International stock market efficiency and integration: A study of eighteen nations", Journal of business finance \& accounting, 24(6), 803-813.

Erdem, Meziyet Sema (2016), “Avrupa Ve Asya-Pasifik Hisse Senedi Pazarlarında Zayıf Formda Pazar Etkinliği Ve Takvim Anomalileri”, AiBÜ Sosyal Bilimler Enstitüsü Dergisi, Cilt:16, Yıl:16, Sayı: 3, 16: 149-166

Ergül, Nuray (2009), “Ulusal Hisse Senedi Piyasasında Etkinlik”, Yönetim Bilimleri Dergisi (7: 1), 101-117

Fama, Eugene F. (1965), "Random Walks in Stock Market Prices", Financial Analysts Journal, Vol. 21, No. 5, 55-59.

Fama, Eugene F. (1970), "Efficient capital markets: A review of theory and empirical work", The journal of Finance, 25(2), 383-417.

Furuoka, Fumitaka (2016), "A new approach to testing unemployment hysteresis", Empirical economics, 1-28.

Gözbaşı, Onur; Küçükkaplan, İlhan; Nazlıoğlu, Şaban (2014), “Re-examining the Turkish stock market efficiency: Evidence from nonlinear unit root tests", Economic Modelling, 38, 381-384.

Kapusuzoglu, Ayhan (2013), "Testing Weak Form Market Efficiency on the Istanbul Stock Exchange (ISE)”, International Journal of Business Management and Economic Research, 4(2), 700-705.

Karan, Mehmet Baha (2011), Yatırım Analizi ve Portföy Yönetimi, Ankara: Gazi Kitabevi.

Kıyılar, Murat (1997), Etkin Pazar Kuramı ve Etkin Pazar Kuramının iMKB'de Irdelenmesi- Test Edilmesi, Ankara: SPK Yayın No:86, Ağustos 1997.

Malkiel, Burton G. (2003), "The efficient market hypothesis and its critics", The Journal of Economic Perspectives, 17(1), 59-82.

Mishra, Ankita; Mishra, Vinod; Smyth, Russell (2015), "The random-walk hypothesis on the Indian stock market”, Emerging Markets Finance and Trade, 51(5), 879-892.

Munir, Qaiser; Ching, Kok Sook; Furouka, Fumitaka; Mansur, Kasım (2012), "The efficient market hypothesis revisited: Evidence from the five small open Asean stock markets", The Singapore Economic Review, 57(03), 1250021.

Narayan, Paresh Kumar (2005), “Are the Australian and New Zealand stock prices nonlinear with a unit root?”, Applied Economics, 37(18), 2161-2166.

Narayan, Paresh Kumar; Smyth, Russell (2004), “Is South Korea's stock market efficient?", Applied Economics Letters, 11(11), 707-710.

Özdemir, Zeynel Abidin (2008), "Efficient market hypothesis: evidence from a small open-economy", Applied Economics, 40(5), 633-641.

Tuna, Gülfen; Öztürk, Mahmut (2016), “Piyasa Etkinliğinin Yapısal Kırılmalı Birim Kök Testleri İle İncelenmesi: Türkiye Pay Senedi Piyasası Uygulaması", Uluslararası Yönetim iktisat ve Işletme Dergisi, 30, 548-559.

Yang, Ginny Ju-Ann; Lee, Chingnun; Lee, Chen-Hsun (2015), "Random Walk in the MIST", Journal of Asia-Pacific Business, 16(2), 92-104.

Zeren, Feyyaz; Konuk, Filiz (2013), "Testing the random walk hypothesis for emerging markets: evidence from linear and non-linear unit root tests", Romanian Economic and Business Review, Vol. 8, No. 4, 61-71. 
Eskişehir Osmangazi Üniversitesi iiBF Dergisi 